\title{
Model to reduce waste in the production of labels in Peruvian companies of the plastic sector by applying Autonomous Maintenance, Kanban and Standardization of work
}

\author{
Gerard Flores ${ }^{1}$, Risso Valenzuela ${ }^{1}$, Gino Viacava, Msc $^{1}$ y Christian del Carpio, Msc $^{2}$ \\ ${ }^{1}$ Industrial Engineering, Universidad Peruana de Ciencias Aplicadas (UPC), Lima - Perú, u201511876@upc.edu.pe, \\ u201420605@upc.edu.pe,pcingvia@upc.edu.pe \\ ${ }^{2}$ Direction of research, Universidad Peruana de Ciencias Aplicadas (UPC), Lima - Perú, pcelcdel@upc.edu.pe
}

\begin{abstract}
This work presents the problem of excessive waste of labels that is generated in the printing of these. The printing process is the key process of the company, since it transforms the plastic rolls together with the inks and an error in the procedures causes the loss of the material entered and money. This drives to propose solutions through Lean techniques in the production of labels. In general, the studies are based on other lines in the plastic sector, such as pipes, bags, containers, among others. To address this problem, the Lean Manufacturing methodology adapted to a cycle of continuous improvement will be used, forming a solution proposal model, with techniques such as support 5s, the application of Autonomous Maintenance, Kanban and Standardization of Work. Based on a pilot test, a waste reduction of $7.78 \%$ and an improvement in the indicators that are involved in the investigation are obtained.
\end{abstract}

Keywords--waste, label production plastic, kanban, autonomous maintenance.

\section{INTRODUCTION}

Currently, the production of the plastic sector is growing on a large scale, obtaining until the year 2030 an annual growth of $4 \%$. Similarly, automation in the sector is increasing due to the cumbersome processes presented by the different lines of the sector [1]. In the national approach, production shows a growth rate with rates greater than $5 \%$, where it is granted greater consumption and investment. It is mentioned that the growth covered almost $40 \%$ of the national import in the last two years [2]. Due to this growth, plastic waste also shows its increase that affects companies and society in general. It is known that the acceptable percentage of losses in the production processes of the industry being studied range between $3 \%$ and $4 \%$. From reviewed research, a percentage of waste of almost double what was acceptable in the sector was achieved in the label line, which is much higher. Due to the increase of the plastic industry, these can increase and be a very arduous problem. It is inferred that there are problems around their rate of production which causes excess waste [3]. Also, different lines of the sector such as pipes, bags, containers, among others, have very high percentages of waste, so the severity of what is presented is high.

Digital Object Identifier (DOI):

http://dx.doi.org/10.18687/LACCEI2020.1.1.96

ISBN: 978-958-52071-4-1 ISSN: 2414-6390
For example, in the line of pipes according to an investigation oriented to the evaluation of the generation of waste, these reached $6.92 \%$, which confirms the aforementioned [4]. Based on the previous efforts of other authors, it is obtained that the low availability of a machine and the stops or technical failures that they present, generate such waste or other problems that affect the company. In this way, the application of different techniques was presented highlighting the Autonomous Maintenance and managed to improve availability by $10 \%$ [5]. Also, the problem of this article and other problems originates due to inadequate production planning, which is aimed at generating overproduction that implies costs for a company and thus the application of Kanban was raised, which decreased the problem by $10 \%$. of this case [6]. Finally, an improvement in working procedures for operators through a standardization of work reduces problems related to excess waste, which through an investigation was improved by $8 \%$ [7].

The company selected for the research project is dedicated to the production of plastic labels, which are frequently used in the final production of beverage bottles, cookies, ice cream, among others. The key process of the elaboration of this product is the printing of the same, which is where the main problem occurs, the excessive generation of waste of labels. Due to this, the importance of studying the losses around the production of labels that, is key for the company, is fundamental.

It was observed that, in 2018, the amount of label waste in the printing area exceeds the policy established by the company that is in the range of $2 \%$ to $3 \%$, which leads to witness a high impact problem in the company and society due to the type of material used in the company. The current diagnosis shows high monthly percentages of waste that were generated by three main causes: the failure of the machines with a $56.15 \%$ impact, due to the inadequate parameters of calibration and the inappropriate use of the personnel, the overproduction with a $39.83 \%$ of impact, due to the inadequate planning of the production and the lack of control of the same, and the inadequate manipulation of the plastic material with a $4.02 \%$ impact, due to the inadequate working methods that currently exist in the study company. In this sense, there is a need to find 
a solution to the dilemma, so the proposal is presented that will reduce the current waste by a large percentage. Likewise, extend the proposal and its level of reliability to the different companies in the sector or other sectors that consider its implementation relevant.

Based on the current problems, the Lean Manufacturing methodology helps to reduce problems through its tools, since at first you must thoroughly understand the concepts of the techniques and their limitations to achieve a successful implementation [8]. This will allow a greater analysis around the factors both external (laws, politics, environment and society) and internal (company size, budget, income, expenses, among others) that may affect the development of the tools. Therefore, the techniques selected with the support of the 5 whys seek to solve specific causes mentioned above. It should be noted that these techniques have in common the human factor, who are in charge of the company's production. Likewise, they will be the ones who will support analysis, development, evaluation and improvements at the end of the implementation.

The use of Lean techniques adapted to a continuous improvement cycle that allows a complete application is proposed. The techniques to be used are autonomous maintenance, the use of Kanban cards and the development of a standardization of work through procedures to present a better workflow for operators. This will be supported by good $5 \mathrm{~s}$ practices, which will contribute to the better management of the implementation of the techniques.

The objective is to reduce the frequent failures of the production machines, present a better workflow of the personnel and correctly execute the planning carried out by those in charge of the area. Thus, it seeks to reduce the waste of labels that are generated in the company studied in order to increase productivity and utility.

The article is structured as follows: section II) gives an overview of the review of the literature on waste in the plastic sector and the use of Lean techniques to counteract this problem, section III) describes the proposed model and how this will be implemented, section IV) the validation of the abovementioned proposal is presented and the results obtained, section V) the discussion of the results and relevant aspects of the investigation is developed, and section VI) make the conclusions of the validation executed In the case of study.

\section{LITERATURE REVIEW}

In the world various companies are growing, due to the competition between them. Also, organizations are looking for new ways to optimize their production or service, so they look for methodologies, tools or techniques to apply them in their organization [9]. For example, it is essential to have information regarding the total remaining waste, which has not been properly evaluated the causes or consequences that are generated around it, since within the production system there are different manufacturing stages which generate losses of the activity [10]. On the other hand, it is presented that the environmental threats of the production waste of the plastic sector arise from the increase in the consumption of the material, where particular plasticizing additive components are considered that are dangerous for human health and the environment [11].

The generation of waste in production is important to analyze, since it is not known in depth the effects that these present in the different sectors of the industry. If the estimates, use and final management are detailed in detail for each specific area and process that generates these wastes, an exhaustive and decisive analysis would be entered into to establish their importance economically [12]. Given this, it is highlighted that it is important to achieve detailed knowledge of waste or waste, since procedures are followed that lead to objectives not initially seen by the organization, where the rate of waste generation in all types of sector is first established in physical and then expands to the entire economy of itself [13]. Likewise, it is highlighted that the companies in the sector under study omit the evaluation of the impacts of waste, so it increases the importance of finding an approach that allows reducing the generation of waste in the production system of an organization [14].

The possible solutions arise from various existing methods, where a means of improvement is the Lean Manufacturing methodology. This philosophy implies that unnecessary activities are identified in the production process in order to reduce or eliminate processes that do not add value to production. Also, the objective is presented to reduce the cost of production, improve the results around productivity [15].

It is worth mentioning that, Lean's thinking is summarized in five principles, precisely specify the concept of value for each specific product, identify the flow of value for each product, make the value flow without interruptions, let the consumer attract to if (Pull) the value from the manufacturer, and pursue perfection [16]. Based on this, it seeks to create value for the products and identify the appropriate production rhythm for them and continue the production sequence without any problem. In addition, create value for end consumers who will appreciate the product and have the decision to buy or return it. Finally, continue in the search for perfection at the time of production and / or distribution.

The application of Lean entails optimizing processes, since performance will be increased with lower consumption of inputs and other resources such as capital, labor, time, raw materials, among others. Also, all unnecessary activities will be eliminated, which means saving the goods and accelerating the 
flow of the production process [17]. However, Lean Manufacturing has different tools and techniques; Therefore, it is necessary to analyze each of these considering the problem and the solution approach that is intended to be applied [18].

It is necessary to have a means of diagnosis which involves observing the entire process and detecting the main problem. Initially, in several studies the Value Stream Mapping (VSM) is used, which is used to map the value chain of the organization [19]. After this analysis, the most appropriate tools are chosen taking into account the limitations of the company. Therefore, the 5s methodology will be used as the basis, which is the fundamental piece for an adequate implementation, because it contains five steps, which are to clean, order, eliminate, standardize and discipline in order to generate a culture of organizational in different areas of the company [20].

The most appropriate technique in the context of production is Kanban, which is a Japanese term, which means instruction label. In it, the relevant information for the production will be centered, which will contain the work order addressing what is intended to be produced and the quantity needed to produce [21]. It is sought to control with the Kanban the flow of production that allows to control and reduce waste or other problems that may be generated by production planning and its corresponding control [5]. It serves to control the progress of work within a production system. This main objective is to manage in a general or specific way each process so that in this way only the necessary is produced. Among its various functions, production control is highlighted [22].

For the context of the machinery, several authors use autonomous maintenance (MA), which has as its main concept that the operators carry out the maintenance of the equipment through procedures and various planned maintenance that prevent the failures in the time established initially; in turn, develop the ability to detect potential machine failures in time [23]. Also, a low availability of the machines is identified by stops and technical failures that generate waste in the different processes involved in the operation of the machine [4]. On the other hand, it is considered important to reduce the downtime of a machine that is preceded by a shutdown, which has a considerable effect on improving productivity and decreases negative impacts such as waste generation [24].

In the human context, Standard Work is used as a means of improvement in this aspect. Industries are looking for ways to improve overall productivity to survive, where standard work is one of the ways to achieve this goal and is defined as the specific instructions that help make a product in the most efficient way. From this, a standard job provides greater flexibility in the production processes and improves a work environment in matters of safety and development in the area [6]. It is important to present a systematic approach with management methods, practices and procedures that influence the work of the operators and the quality of work [25].

However, a limited part of the literature has focused on other important concerns, such as barriers to implementation in SMEs [26]. Given this, the present limits or barriers of the companies are taken into account before an implementation of the Lean methodology, since it is necessary to know the difficulties present when developing Lean within the organization. Likewise, the type of company must be known, whether in size, production system, personnel, among others, in order to determine necessary improvements taking into account the limitations within your organization. This is relevant, since the human factor is the important part of the organization where employees at all levels must be aware of the application of this methodology.

\section{PROPOSED MODEL}

The research project is carried out based on the identification of an excess of waste of label solutions that are generated in their production. The printing of this material is the key process of the company, so the virgin plastic roll, the inks and the clisses that present the designs required by the client are mixed, and an error in the procedures to be developed leads to the label is automatically discarded. These wastes are due to several factors, of which the machine failure, the lack of a production control and inadequate procedures for the development of the work of the personnel stand out. In this sense, it is essential to develop a model that allows reducing the negative impact at the productive and economic level that is generated in the company through the application of engineering techniques.

The proposed solution proposed in the article will be divided into three phases, which will be adapted to the continuous improvement cycle, since the implementation of said proposal is a constant improvement for the company. The general design of the proposal is shown in Fig. 1.

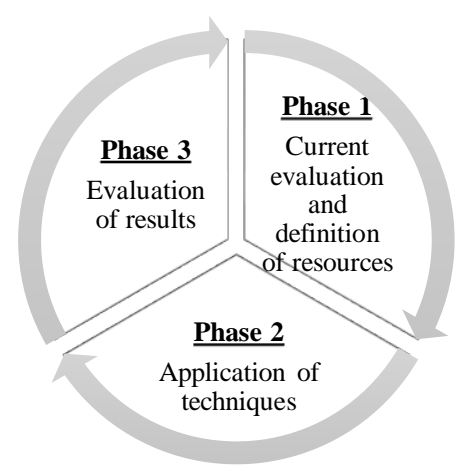

Fig. 1 General design of the proposed model 
The general view of the proposal presents Phase 1 that includes the current diagnosis of the company that evidences the problem and based on this define the resources that are required and that are accessible to implement the proposed model. Then, Phase 2 is the application of the techniques that the model presents following the procedures and formats previously established. Finally, Phase 3 is the analysis of results and the presentation of actions to use a constant improvement.

The first phase of the proposal is adapted to the first step of continuous improvement, which is to plan. The sequence to follow in the development of this phase is presented in Fig. 2.

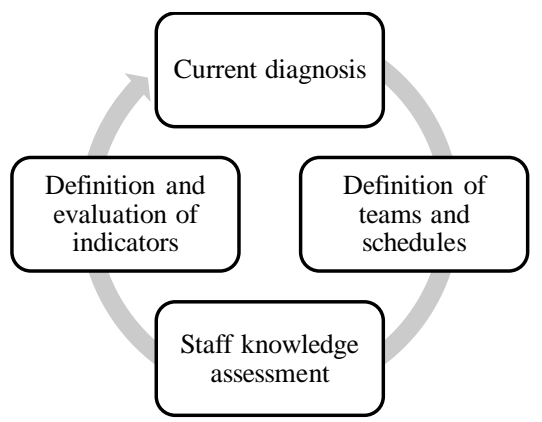

Fig. 2 Development of the first phase of the proposal

In the first place, by means of the current diagnosis that is made to the company, the research problem and the causes that originate it are determined. Secondly, it defines the personnel that will contribute to the realization of the project and determine the different schedules that are needed in the implementation. Thirdly, through surveys, evaluate the selected personnel on whether they present any knowledge of the techniques that will be used in the solution proposal. Finally, define and clarify the indicators that will assess the degree of success of the proposal after its implementation knowing its current percentages.

The second phase of the proposal is adapted to the second and third step of the continuous improvement cycle, which are done and verified. In this sense, the Lean techniques to be used in the proposal will be presented, which will be detailed below.

The support for the correct implementation of the three techniques aimed at attacking each cause of the problem is the $5 \mathrm{~s}$. Through this good practice, it seeks to carry out an orderly, clean and oriented execution for the best performance of the personnel. The application of the $5 \mathrm{~s}$ is derived in four stages.

As a first stage, staff training is presented. The second stage is to monitor and evaluate the personnel on their performance when performing this good practice. The third stage consists of the application of the five tasks presented by this good practice, which will be presented in Table I.
TABLE I

DEVELOPMENT OF THE TASKS TO BE IMPLEMENTED

\begin{tabular}{|c|c|l|}
\hline $\mathbf{N}^{\circ}$ & Homework & \multicolumn{1}{|c|}{ Development } \\
\hline 1 & Sort out & $\begin{array}{l}\text { Examine the current status of existing elements in } \\
\text { the study area. }\end{array}$ \\
\hline 2 & Organize & Locate resources in strategic places. \\
\hline 3 & Clean & $\begin{array}{l}\text { Apply through correct procedures the cleaning of } \\
\text { company resources. }\end{array}$ \\
\hline 4 & Standardize & $\begin{array}{l}\text { Standardize general procedures that preserve the } \\
\text { above tasks. }\end{array}$ \\
\hline 5 & Discipline & $\begin{array}{l}\text { Oriented to the creation of habits and constant } \\
\text { application of this good practice. }\end{array}$ \\
\hline
\end{tabular}

As a last stage, the audits are presented, which is fundamentally the analysis of the results obtained in the evaluations.

\section{AUTONOMOUS MAINTENANCE}

The current maintenance flow of the company is basically oriented towards the application of corrective actions after a machine failure. These failures are related to adjustments and calibrations that generate the stop of the machine and that course causes the loss of labels.

The techniques mentioned will follow three stages. As a first stage, the mapping of the process that arises in the machine with failures is presented. The second stage is oriented to the execution of the MA steps, which will be applied with different tools. In this sense, the steps mentioned in Table II will be detailed.

TABLE II

DEVELOPMENT OF THE STEPS OF AUTONOMOUS MAINTENANCE

\begin{tabular}{|c|c|l|}
\hline $\mathbf{N}^{\circ}$ & Homework & \multicolumn{1}{|c|}{ Development } \\
\hline 1 & Initial cleaning & $\begin{array}{l}\text { Submit cleaning instructions using a } \\
\text { previously established format. }\end{array}$ \\
\hline 2 & Dirt removal & $\begin{array}{c}\text { Maintain in optimal conditions the } \\
\text { elements that interact with the machines. }\end{array}$ \\
\hline 4 & $\begin{array}{c}\text { General inspection } \\
\text { lubrication }\end{array}$ & $\begin{array}{l}\text { Apply Visual Management that allows } \\
\text { rapid detection of problem in the machine. }\end{array}$ \\
\hline 5 & $\begin{array}{c}\text { Autonomous } \\
\text { inspection }\end{array}$ & $\begin{array}{l}\text { Develop a sense of operator autonomy } \\
\text { through report cards. }\end{array}$ \\
\hline 6 & $\begin{array}{c}\text { Control and } \\
\text { organization }\end{array}$ & $\begin{array}{l}\text { Use the verification sheets to evaluate the } \\
\text { development of the previous steps. }\end{array}$ \\
\hline 7 & $\begin{array}{c}\text { Autonomous } \\
\text { Management }\end{array}$ & $\begin{array}{l}\text { Oriented to the creation of habits and } \\
\text { constant application of this technique. }\end{array}$ \\
\hline
\end{tabular}

As a last stage, the analysis of the results obtained that demonstrate the effectiveness of the implementation of the MA is carried out. This will be done with the help of the "DOM" indicator that will be detailed in (1). 


$$
D O_{M}=\frac{\operatorname{Hrs} P A}{\operatorname{Hrs} D M} \times 100 \%
$$

Where:

$$
\begin{array}{llll}
- & \mathrm{DO}_{\mathrm{M}} & : & \text { Machine Operational Availability } \\
\text { - } & \text { Hrs PA } & : & \text { Hours Stop by Breakdown } \\
\text { - } & \text { Hrs DM } & : & \text { Machine Available Hours }
\end{array}
$$

The indicator presented is expected to generate an improvement greater than $10 \%$, which is based on the result obtained in other research and in this regard, it seeks to exceed that established percentage.

\section{KANBAN}

This technique works through cards, which inform about the needs in terms of materials, spare parts or products. This has the main function of production control and this implies the integration of the different processes [27]. Next, the implementation phases are shown in Fig. 3.

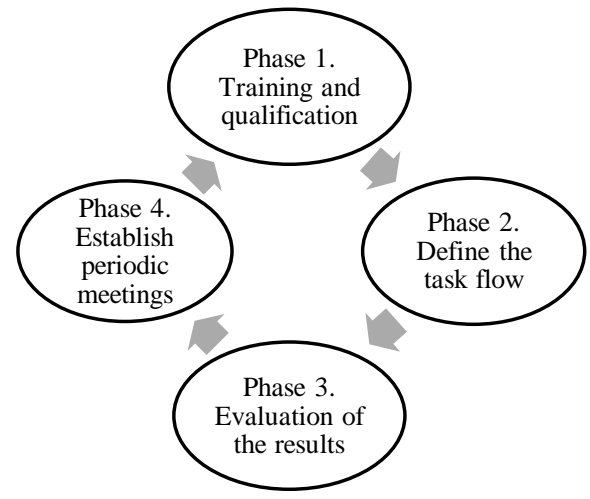

Fig. 3 Phases of the Kanban

Kanban implementation will follow four phases. As a first phase, the training and training is presented, which is developed with weekly workshops and talks. As a second phase, there is the definition of the task flow and implementation of Kanban cards that allow controlling and visualizing the production situation and its relationship between the planned and the actual one. As a third phase, the evaluation of the results obtained is presented and to verify if the proposal is fulfilled from the measurement of the "SP" indicator, which will be detailed in (2). It is important to present a minimum value, since production exceeds one million planned labels.

$$
S P=\frac{C S P}{C P L} \times 100 \%
$$

Where:

$$
\begin{array}{llll}
- & \text { SP } & \text { : } & \text { Overproduction } \\
\text { - } & \text { CSP } & : & \text { Overproduced Quantity } \\
\text { - } & \text { CPL } & : & \text { Planned Amount }
\end{array}
$$

The indicator presented is expected to generate an improvement greater than $10 \%$, which is based on the result obtained in other research and thus, it seeks to exceed that established percentage. Finally, the last phase is to establish periodic meetings.

\section{STANDARD WORK}

The Standard Work seeks to increase labor productivity based on standardized work in a productive process. This is relevant, because it is necessary for staff to know and adapt to a more efficient way of working. Therefore, the solution proposal will be adapted taking into account the main problem, which is the excess of label waste which is caused by improper handling of materials that, in turn, is caused by an inadequate working method. Given this, it is necessary to know the requirements of Standard Work in order to demonstrate the feasibility of execution.

- Work tasks must be repetitive.

- Provide a commitment on the part of the collaborators towards the work.

- Discipline on the part of the operators and orientation of the area of the headquarters for a monitoring of the performance.

The procedure that follows is the one shown in the following Fig. 4.

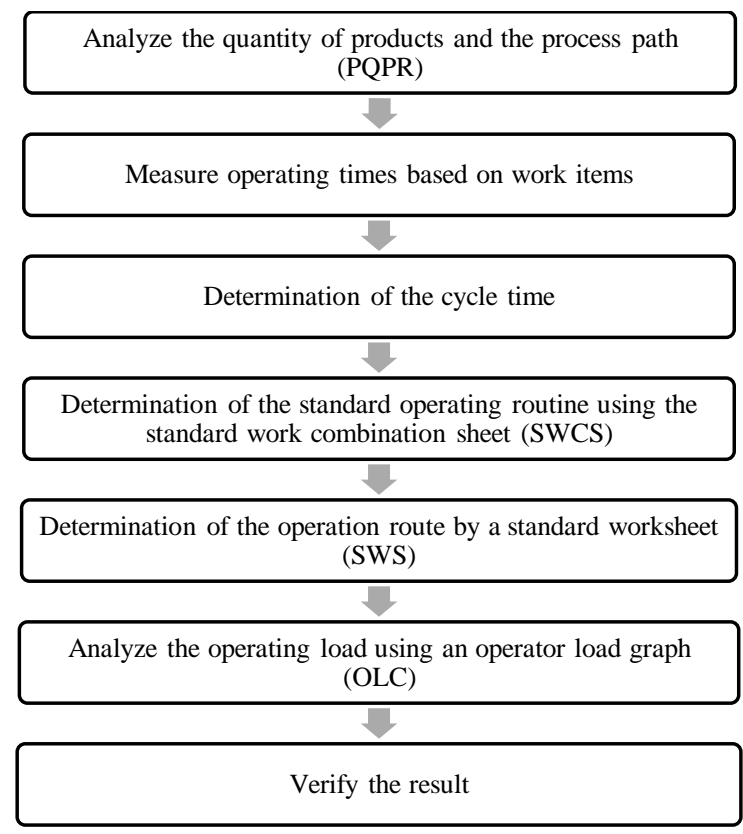

Fig. 4 Standard Work Procedure

After the execution of the procedures, these will be evaluated with the indicator "Damages" that are generated in the activities of the operators and will be detailed in (3). In this 
way, the results are analyzed and improvement actions are taken.

$$
D=\frac{C U D}{T C} \times 100 \%
$$

Where:

$\begin{array}{llll}- & \text { D } & : & \text { Damage } \\ - & \text { CUD } & : & \text { Number of Units Damaged } \\ - & \text { TC } & : & \text { Total Amounts }\end{array}$

The indicator presented is expected to generate an improvement greater than $8 \%$, which is based on the result obtained in other research and in this way, it is sought to exceed said established percentage.

The last and third phase is the analysis of the results that will be obtained from the pilot test compared to the current diagnosis that allows to prove if the proposed solution is feasible for an improvement of the indicators and from there present actions that allow to establish an improvement Continue and meet the objectives set initially.

\section{VALIDATION}

To validate the proposal, the pilot test and a simulation were carried out, in order to compare a before and after following the phases established in the solution proposal. The data comes from the print tracking of the shrink labels. Likewise, a sampling of time was carried out for each process that involves printing and to be able to properly evaluate the indicators involved.

The process begins when the supplies are in the warehouse such as virgin labels and inks. Then, it goes to the material reception area, in which the current state of the elements is validated. Then, it goes to the weighing area in which the number of rolls of labels to be introduced to the machine is estimated. In the next station you have the impression, in which they are responsible for placing the rolls and inks in the machine. Then, it passes the inspection area where the collaborators examine the labels and separate those that have defects. Then, there is the cutting area where the same operators cut the shrink labels. Finally, there is the packaging in which the operators gather the printed labels and deposit it in another area for the corresponding dispatch.

The main problem detected in the company is the high percentage of label waste that occurs in said process, exceeding the percentage of waste in the sector and the policy established by the company, mentioned in detail in the introduction. The analysis of the data is based solely on the shrink labels, which represents $48.55 \%$ of waste in the current diagnosis.
These percentages of waste are calculated based on daily production reports that are recorded manually. Using this format, the percentage of monthly form shown in Fig. 5 is analyzed.

From Fig. 5, it is determined that the average monthly waste of the case study amounts to $5.77 \%$. In this sense, the problem in the defined production process is important to examine and evaluate the indicators involved.

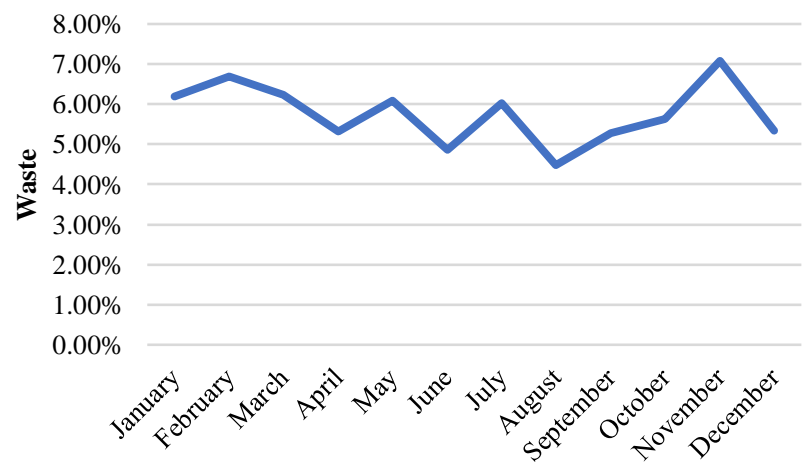

Fig. 5 Monthly percentages of heat shrink label waste

The results obtained from the pilot plan are based on two months of execution, which were September and October of the year 2019. The data to analyze the production and the improvement of the indicators arose from the daily production reports made by the operators. Table III shows the planning and general waste that were obtained.

TABLE III GENERAL ANALYSIS OF PRODUCTION

\begin{tabular}{|c|c|c|c|}
\hline Month & $\begin{array}{c}\text { Planned } \\
\text { Length (m) }\end{array}$ & $\begin{array}{c}\text { Failure } \\
\text { Length (m) }\end{array}$ & $\begin{array}{c}\text { Label waste } \\
\text { percentage }\end{array}$ \\
\hline September & 1178600 & 62700 & $5.32 \%$ \\
\hline October & 1097000 & 58300 & $5.31 \%$ \\
\hline
\end{tabular}

In the evaluation of the indicators, the variables presented by each formula described in the solution proposal are considered using detailed resources such as formats, procedures, visual procedures, among others. It is important to emphasize that the data obtained on average is worked, so a comparison is made between the analyzed average of the year 2018 with the average of two months that is carried out in the pilot. Thus, Table IV is obtained where the before and after the indicators are presented with the general percentage of improvement. 
TABLE IV

COMPARISON OF THE INDICATORS OF THE PROJECT IN PILOT

\begin{tabular}{|c|c|c|c|}
\hline Indicator & Before & After & $\begin{array}{c}\% \\
\text { improvement }\end{array}$ \\
\hline DOM & $33.62 \%$ & $35.81 \%$ & $6.12 \%$ \\
\hline SP & $2.07 \%$ & $2.02 \%$ & $2.4 \%$ \\
\hline D & $14.87 \%$ & $9.59 \%$ & $35.5 \%$ \\
\hline 5s Audit & $45.45 \%$ & $67.27 \%$ & $32.44 \%$ \\
\hline
\end{tabular}

The general result of the reduction of heat shrinkable waste is presented in Table $\mathrm{V}$.

TABLE V

GENERAL RESULT OF THE REDUCTION OF WASTE OF LABELS IN PILOT

\begin{tabular}{|c|c|c|c|}
\hline $\begin{array}{c}\text { General } \\
\text { evaluation }\end{array}$ & $\begin{array}{c}\mathbf{2 0 1 8} \\
\text { Average }\end{array}$ & $\begin{array}{c}\text { Pilot } \\
\text { Average }\end{array}$ & $\begin{array}{c}\text { \% } \\
\text { improvement }\end{array}$ \\
\hline $\begin{array}{c}\text { Waste } \\
\text { percentage }\end{array}$ & $5.77 \%$ & $5.32 \%$ & $7.78 \%$ \\
\hline
\end{tabular}

Based on Table $\mathrm{V}$, it is determined that the impact is a $16.02 \%$ reduction in waste from heat shrinkable labels, which makes it possible to verify that the proposed solution is still viable. However, it is important to emphasize that these results may vary, since the pilot is only two months and the data compared to the current diagnosis may allow the improvement to increase or decrease in a few months.

The results obtained from the simulation performed show the comparison of a long-term before and after. The data comes from the print tracking of a shrink label where time sampling of each process involving printing was performed. Thus, Table VI is obtained where the improvement of the indicators is presented.

TABLE VI

COMPARISON OF THE PROJECT INDICATORS IN SIMULATION

\begin{tabular}{|c|c|c|c|}
\hline Indicator & Before & After & $\begin{array}{c}\text { \% } \\
\text { improvement }\end{array}$ \\
\hline DO $_{\mathbf{M}}$ & $33.62 \%$ & $49.50 \%$ & $32.08 \%$ \\
\hline $\mathbf{S P}$ & $2.07 \%$ & $2.50 \%$ & $-20.8 \%$ \\
\hline $\mathbf{D}$ & $14.87 \%$ & $3.52 \%$ & $70.3 \%$ \\
\hline
\end{tabular}

The general result of the reduction of heat shrinkable waste is presented in Table VII. Based on Table VII, it is determined that the impact is $16.64 \%$ reduction in waste from thermo shrinkable labels, which allows verifying that the solution proposal is also feasible in the simulation.
TABLE VII

GENERAL RESULT OF THE REDUCTION OF WASTE OF LABELS IN SIMULATION

\begin{tabular}{|c|c|c|c|}
\hline $\begin{array}{c}\text { General } \\
\text { evaluation }\end{array}$ & $\begin{array}{c}\mathbf{2 0 1 8} \\
\text { Average }\end{array}$ & $\begin{array}{c}\text { Pilot } \\
\text { Average }\end{array}$ & $\begin{array}{c}\% \\
\text { improvement }\end{array}$ \\
\hline $\begin{array}{c}\text { Waste } \\
\text { percentage }\end{array}$ & $5.77 \%$ & $5.30 \%$ & $8.08 \%$ \\
\hline
\end{tabular}

It should be noted that the "Overproduction" indicator increases its impact on the problem because the technique for solving this cause is not controlled in the simulation.

\section{DISCUSSION}

The result of a general improvement in the reduction of label waste is $7.78 \%$ but this can be affected by several very important factors. First, it is important to mention that the pilot carried out was only executed in two months, obtaining the data already presented in the validation. The current diagnosis was based on data from the whole year 2018, so the results obtained have a more real average. In this sense, the comparison that was made in the validation is based on an average analysis of the results of the pilot plan as of the current situation. However, since the pilot plan is only for two months, the general results can be affected positively or negatively if the execution of the established plan is carried out for more months and then a new analysis of general improvement of the label waste reduction is presented. Secondly, the rotation of machine operators can affect the correct implementation of the solution proposal, so according to the filter made in the diagnosis of the problem, the research is based on the shrink labels produced on selected machines. It should be noted that it works with heat shrinkage, since it is the type of product that exhibits the greatest amount of waste, presents the most important customers and generates the largest number of orders for the company. In this way, if there is rotation of operators, it would start from the beginning to the execution of the pilot and the development of activities which would delay the increase in the improvement of waste reduction. Finally, the improvement can be considerably increased if the inclusion to the production area of a specialist technician of the machine is evaluated, since according to the analysis of the current situation, the highest percentage of the causes that generate the problem is caused by the failure of the machines and their excessive stops. Thus, including a technician would be vital to control these failures and this according to a simulation performed, would improve the availability of the machine by $32.08 \%$. It should be noted that the result obtained from the simulation is in a longer evaluation time to the pilot, so in the long term the execution of the proposal including the complete project will provide optimal results.

Regarding the indicators, it is observed in the validation that there are improvements in each of them. It is verified that the indicator "Damages" oriented to the inadequate manipulation

$18^{\text {th }}$ LACCEI International Multi-Conference for Engineering, Education, and Technology: "Engineering, Integration, and Alliances for a Sustainable Development" "Hemispheric Cooperation for Competitiveness and Prosperity on a Knowledge-Based Economy", 29-31 July 2020, Buenos Aires, Argentina. 
of material by the operators presents an improvement well above the proposed objective, since the application of the technique of standardization of work was feasible. Here, compliance with the procedures to treat the virgin label was developed with an exhaustive follow-up, which led to a routine culture that allows the operator to use all available resources to carefully move and handle the plastic rolls. However, the other two indicators, "Operational Availability of the Machine" and "Overproduction" do not exceed the stated objective, since they influence the time of the pilot performed and the willingness of the operators to make the proposed procedures effective. This produces that the improvement for each indicator is minimal but provides optimal results that allow further development of the proposed solution.

The analysis of results for each indicator in other scenarios is based on the type of machine used and the type of material used in the line to be evaluated. The matrix of indicators improvements will be shown in Table VIII where 1 is minimal improvement, 3 considerable improvement and 5 total improvement.

TABLE VIII

MATRIX FOR IMPROVING INDICATORS IN DIFFERENT SCENARIOS

\begin{tabular}{|c|c|c|c|}
\hline Stage & DOM $_{\mathbf{M}}$ & SP & D \\
\hline Labels & 1 & 1 & 5 \\
\hline Pipelines & 3 & 5 & 5 \\
\hline Bags & 1 & 3 & 5 \\
\hline
\end{tabular}

Based on the analysis in Table VIII, the impact of the indicators in the different scenarios is presented. On the one hand, the Operational Availability of the Machine is considered in the same way for the labels and bags in a minimal improvement due to the result obtained in the pilot plan and the similarity of the characteristics presented by the equipment for this type of material. In relation to pipes, the technical specifications allow fewer stops due to breakdowns. On the other hand, Overproduction on labels is at greater risk because they are produced by type of product and based on customer specifications. However, in the other two scenarios they present standardized products that often omit an overproduction. Finally, the Damages of the material due to an inadequate manipulation in the three scenarios present total improvements, because it is directly related to the work of the operator, which, with procedures and follow-ups to their activities, these results can be achieved.

\section{CONCLUSIONS}

For the label production company, the problem of excess label waste in the production area was identified with a 5.77\% average waste, a value that exceeds the company's policy and acceptable parameters in the sector. Based on what has been described, the implementation of the pilot considering techniques such as the Autonomous Maintenance that attacks the machine failure cause, allowed the machine's availability to increase by $6.12 \%$. Also, the application of Kanban caused the overproduction to decrease by $2.4 \%$. Finally, the execution of the Standardization of work generated that the percentage of damages due to improper handling of the labels is reduced by $35.5 \%$. In general, waste reduction was carried out by $7.78 \%$. It should be noted that it is far from the objective that is to completely eliminate waste, however, it is important to mention that in order to reach the objective all the developed resources would have to be applied and the proposal implemented in its entirety, covering a considerable investment. The direct improvement in the reduction of the type of shrink label is $16.02 \%$. This value indicates notable improvements for the investigation but not sufficient, so that value is only related to $48.55 \%$ which represents the type of label mentioned in relation to the total products handled by the company.

Based on the simulation presented, it is determined that the improvement obtained is $8.08 \%$, which has an impact of $16.64 \%$ reduction in waste from heat shrinkable labels, which allows verifying that the solution proposal is also viable in the simulation. It is important to mention that in the simulation if an additional resource is considered that is the machineoriented technician, which provides favorable results by improving the DOM indicator by $32.08 \%$.

The analysis of impacts generated by the research is based on selecting a suitable staff and complying with the established procedures to strengthen their knowledge and skills, and generate greater control in the night time. Also, apply the project taking care of the environment, since it directly affects the soil and air various materials and supplies that are used in the production of labels.

\section{REFERENCES}

[1] Collantes, Leyva, Mejía, Ruíz (2017) Planeamiento Estratégico de la Industria Peruana del Plástico. (Tesis para obtener el grado de magíster). Pontificia Universidad Católica del Perú (PUCP). Lima, Perú.

[2] Mamani, L. (2018). Optimización del Proceso Productivo en el Área de Producción de una industria Plástica. Universidad Peruana de Ciencias Aplicadas (UPC), Lima, Perú. https://doi.org/10.19083/tesis/624502

[3] Villaverde Martínez, J. (2012). Propuesta de implementación de los 14 principios del Dr. Deming en una empresa de envases y envolturas plásticas. Propuesta de implementación de los 14 principios del Dr. Deming en una empresa de envases y envolturas plásticas. Lima, Lima, Lima: PUCP.

[4] Heredia, A. (2016, p.19) Reducción de mermas en la producción de sacos de polipropileno para la mejora de la productividad en la empresa El Águila S.R.L. (Tesis de titulación). Universidad Católica de Santo Toribio de Mogrovejo (USAT). Chiclayo, Perú.

[5] Guariente, P., Antoniolli, I., Ferreira, L. P., Pereira, T., \& Silva, F. J. G. (2017). Implementing autonomous maintenance in an automotive components manufacturer. Procedia Manufacturing, 13, 1128-1134. doi:10.1016/j.promfg.2017.09.174 
[6] Sabaghi, M., Rostamzadeh, Reza., Mascle, C. (2015) Kanban and value stream mapping analysis in lean manufacturing philosophy via simulation: a plastic fabrication (case study). Int. J. Services and Operations Management, 20 ( 1), 118-140

[7] Rahul S. M., Arvind, B., Sarbjit, S., \& Anish, S. (2018). Productivity gains through standardization-of-work in a manufacturing company. Journal of Manufacturing Technology Management.

[8] Sarria, M. P., Fonseca, G. A. \& Bocanegra, C. C., (2017). Modelo metodológico de implementación de lean manufacturing. Revista EAN, 83, 51-71.

[9] Reynolds, C., Geschke, A., Piantadosi, J., \& Boland, J. (2016). Estimating industrial solid waste and municipal solid waste data at high resolution using economic accounts: An input-output approach with australian case study. The Journal of Material Cycles and Waste Management, 18(4), 677686.

[10]Halimatussa'diah, A. \& Muchamad, S. (2017). Productivity improvement in the production line with lean manufacturing approach: case study PT. XYZ. MATEC Web of Conferences

[11]Comanita, E., Hlihor, R., Ghinea, C. y Gavrilescu, M. (2016). Occurrence of plastic waste in the Environment: ecological and health risks. Environmental Engineering \& Management Journal (EEMJ), 15(3), 675685, https://doi.org/10.30638/eemj.2016.073

[12]Geyer, R., Jambeck, J. y Lavender, K. (2017). Production, use, and fate of all plastics ever made. American Association for the Advancement of Science. 3(7), 1010-1017. https://doi.org/10.1126/sciadv.1700782

[13]K. Gálová, R. Rajnoha, P. Ondra (2018) The use of industrial Lean Management methods in the economics practice: an empirical study of the production companies in the Czech Republic. Polish Journal of Managment Studies, 17(1), 93-104. http://doi.org/10.17512/pjms.2018.17.1.08

[14]Umer, M.; Abid, M. (2017) Economic practices in Plastic Industry from raw material to waste in Pakistán: A case Study. Asian Journal of Water Environment and Pollution, 14(2), 81-90. https://doi.org/10.3233/AJW170018

[15]Silva, A, J. \& Salas, R, F. (2017). Application of Lean Techniques to Reduce Preparation Times: Case Study of a Peruvian Plastic Company. International Journal of Applied Engineering Research. Volume 12, Number 23 (2017) pp. 13541-13551.

[16]Womack, J. P., y Jones, D. T., (2005). LEAN THINKING, Como utilizar el pensamiento Lean para eliminar los depilfarros y crear valor en la empresa. Espana Barcelona, Gestión 2000

[17]Haq, M. A., Khan, N. R., Parkash, R., \& Jabeen, A. (2016). Impact of JIT, waste minimization, and flow management on operational performance of manufacturing companies. Calitatea, 17(153), 48-52

[18]Lacerda, A. P., Xambre, A. R. \&Alvelos, H. M., (2016). Applying Value Stream Mapping eliminate waste: a case study of original equipment manufactures the automotive Industry. International Journal of Production Research. 54(6), 1708-1720

[19]Vinod, Y. Rakesh, J. Murari, A. Panwar, Milin, k., (2019) "An appraisal on barriers to implementó lean in SMEs", Journal of Manufacturing Technology Management, Vol. 30 Issue: 1, pp.195-212.

[20]Kumar, S., Dhingra, A. y Singh, B. (2018). Kaizen Selection for Continuous Improvement through VSM-Fuzzy-TOPSIS in Small-Scale Enterprises: An Indian Case Study. Advances in Fuzzy Systems. 1-10.

[21]Katarzyna, A.\& Dorota, S. (2017). Lean Philosophy Implementation in SMEs - Study Results. Procedia Engineering.

[22][20] Magdalena K. W, \& Beata, M. (2017). Mirages of Lean Manufacturing in Practice. Procedia Engineering,182 (1) 780-785

[23]Nallusamy, S. y Majumdar, G. (2017). Enhancement of Overall Equipment Effectiveness using Total Productive Maintenance in a Manufacturing Industry. International Journal of Performability Engineering, 13(2), 173188.

[24]Nwanya, S. C., Udofia, J. I. y Ajayi, O. O. (2017). Optimization of machine downtime in the plastic manufacturing. Cogent Engineering. 4(1). 1. https://doi.org/10.1080/23311916.2017.1335444

[25]Tortorella, Guilherme, Lizandra Vergara, Evelise Ferreira (2017). "Lean Manufacturing Implementation: An assessment Method with Regars to Socio-Technical and Ergonomics Practices Adoption". International of Advanced Manufacturing Technology 89(9-12): 3407-18. Doi: 10.1007/s00170-016-9227-7.
[26]Vinod Yadav, Rakesh Jain, Murari Lal Mittal, Avinash Panwar and Milind Kumar Sharm. (2019) An appraisal on barriers to implement lean in SMES's. Journal of Manufacturing Technology Management.

[27]Arango, M. D., Campuzano, L. F. \& Zapata, J. A., (2015). Mejoramiento de procesos de manufactura utilizando Kanban. Revistas Ingenierías Universidad de Medellin. 14(27). 